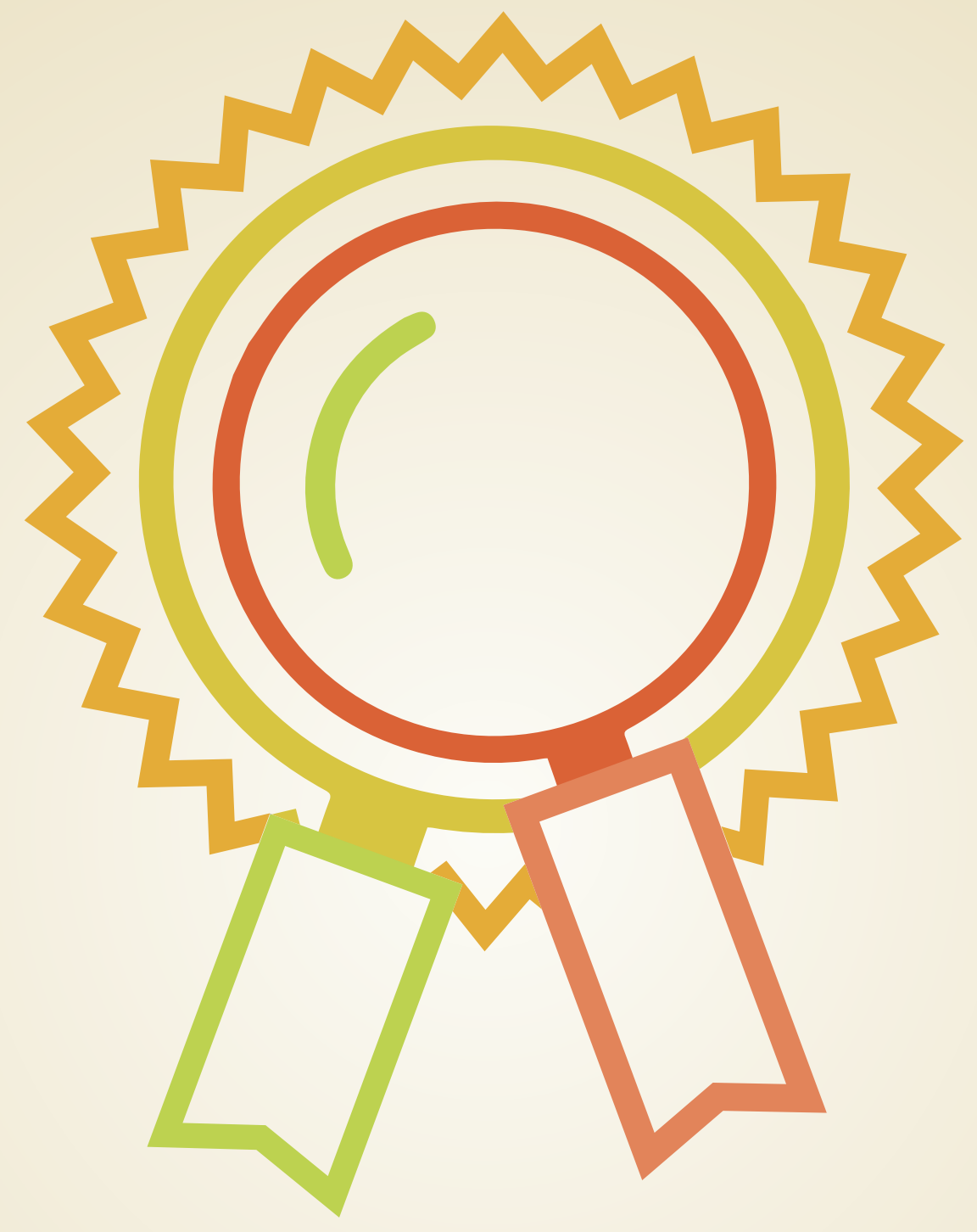

Judging Research How Should Research \& Researchers Be Evaluated and Rewarded?

The 2019 MDPI Writing Prize 


\section{Judging Research}

The 2019 MDPI Writing Prize 


\section{The MDPI Writing Prize Series Volume 2}

SERIES EDITOR

Martyn Rittman

The MDPI writing prize aims to promote excellence in scientific writing and explore themes relevant to early career researchers. The inaugural edition took place in 2019 and saw over 40 entries from across the globe. All participants are given the option to publish their entry in an open access book. 
Martyn Rittman (Ed.)

\section{Judging Research}

How Should Research and Researchers Be Evaluated and Rewarded?

\section{The 2019 MDPI Writing Prize}




\section{SERIES EDITOR}

Martyn Rittman

MDPI

Basel, Switzerland

\section{EDITORIAL OFFICE}

MDPI

St. Alban-Anlage 66

4052 Basel, Switzerland

For citation purposes, cite each chapter independently as indicated on the chapter page online and as indicated below:

LastName, A.A.; LastName, B.B.; LastName, C.C. Chapter Title. In Judging Research: How Should Research and Researchers Be Evaluated and Rewarded? The 2019 MDPI Writing Prize; Martyn Rittman, Ed., The MDPI Writing Prize Series, Martyn Rittman, Ed.; MDPI: Basel, Switzerland, 2020; Volume 2, Page Range.

VOLUME 2

ISBN 978-3-03928-314-9 (PBK)

ISBN 978-3-03928-315-6 (PDF)
ISSN 2624-9693 (Print)

ISSN 2624-9693 (Online)

Cover image courtesy of MDPI.

(C) 2020 by the authors. Chapters in this book are Open Access and distributed under the Creative Commons Attribution (CC BY 4.0) license, which allows users to download, copy and build upon published articles, as long as the author and publisher are properly credited, which ensures maximum dissemination and a wider impact of our publications.

The book as a whole is (C) 2020 MDPI under the terms and conditions of the Creative Commons license CC BY-NC-ND 4.0 . 


\section{Contents}

List of Contributors $\quad$ vii

About the Series Editor $\quad$ ix

Preface to "Judging Research: How Should Research and Researchers Be Evaluated and Rewarded?"

1 Incentives, Rewards, and Recognition - What Really Motivates a Researcher? Nils A. Nilsson

2 How to Evaluate and Reward Science and Technology Researchers Qi Zhang

3 Scientific Metrics: How Useful Are They? Igor Ogashawara

4 Tangible and Non-Tangible Rewards- a Balancing Act Magaret Sivapragasam

5 Judging and Rewarding Research and Researchers: Beyond Bibliometrics Arvind Sharma

6 Judging Research in the Doors of Irreproducibility Crisis Era José L. Flores-Guerrero

7 Should the Quality of the Journal Determine the Quality of the Research? Ahmet Yüksek

8 Judging Research: How Should Research and Researchers Be Evaluated and Rewarded? Ajna Bihorac

9 Open Science, Sustainability and Qualitative Assessment of Merit for an Objective Evaluation of Research

Roberta Gualtierotti

10 Impact Factor $\neq$ Impact: Lessons Learned from Research Evaluation Luca D. Bertzbach

11 Incentives, Rewards, and Recognition - What Really Motivates a Researcher? Valentina Ghimpau

12 Mathematics in Current Science and in Scientific Evaluation Irma Ayes Rivera

13 Achievement of the Paper and Its Honor for a Researcher Aqiang Lin

14 Judging Research: Is There Even a Need of Evaluating the Research? Prashant Chauhan

15 Research Quality and How to Find It? Luisa Rojas 
16 Judging Research: How Should Research and Researchers Be Evaluated and Rewarded?

Fenik Kaml Muhammed

17 Judging Research: How Should Research and Researchers Be Evaluated and Rewarded? Subhan Danish 


\section{List of Contributors}

YÜKSEK, AHMET. Bozok University, Faculty of Medicine, Anesthesiology and Reanimation, Ataturk road 7th KM. Yozgat, Turkey; ahmetyuksek@yandex.com.

BIHORAC, AJNA. PhD student, Institute of Genetics and Animal Breeding, Postepu 36A, Jastrzebiec, 05-552 Magdalenka, Poland; a.bihorac@ighz.pl.

LIN, AQIANG. College of Power and Energy Engineering, Harbin Engineering University, China; linaqiang@hrbeu.edu.cn.

SHARMA, ARVIND. PhD student, School of Veterinary Science, The University of Queensland, 8134, Merv Young White House, Centre for Animal Welfare \& Ethics, Gatton Campus, 4343, Australia; arvind.sharma@uqconnect.edu.au.

FENIK K., MUHAMMED. PhD student, Orthodontic Department, School and Hospital of Stomatology, China Medical University, Shenyang, 110002, China; fenik@cmu.edu.cn. Erbil Polytechnic University, Kurdistan Region, Erbil, 44011, Iraq; fenik.muhammed@epu.edu.iq.

OGASHAWARA, IGOR. Department of Earth Sciences, Indiana University - Purdue University Indianapolis, 723 West Michigan Street, SL118, 46202, Indianapolis, Indiana, USA; igorogas@iu.edu.

AYES RIVERA, IRMA. Postgraduation program CLIAMB, Instituto Nacional de Pesquisas da Amazônia (INPA)-Universidade do Estado do Amazonas (UEA), Ave. André Araújo, 2936, Manaus CEP 69060-001, Brazil; ayesrivera@hotmail.com.

FLORES-GUERRERO, JOSÉ. Nephrology Department, University Medical Center Groningen Hanzeplein 1, 9713 GZ Groningen, The Netherlands; j.l.flores.guerrero@umcg.nl.

BERTZBACH, LUCA. Freie Universität Berlin, Institut für Virologie, Robert-von-Ostertag-Straße 7-13, 14163 Berlin, Germany; luca.bertzbach@fu-berlin.de.

ROJAS, LUISA. University of Arizona, 425 N 5st. Phoenix, Arizona; 1mrojas@email.arizona.edu.

SIVAPRAGASAM, MAGARET. Postdoctoral Research Scientist, Centre of Research in Ionic Liquids (CORIL), Universiti Teknologi PETRONAS, Seri Iskandar, 32610, Perak, Malaysia; magaret_62@yahoo.co.uk.

NILSSON, NILS. National Centre for Nuclear Research, ul. Pasteura 7, 00-293, Warsaw, Poland; albin.nilsson@ncbj.gov.pl.

CHAUHAN, PRASHANT. National Center for Cell Science (NCCS), Pune, India; pra751990@gmail.com.

ZHANG, QI. School of Control Science and Engineering, Shandong University, 17,923 Jingshi Road, Jinan 250061, Shandong Province, China; zhangqi2013@sdu.edu.cn.

GUALTIEROTTI, ROBERTA. Department of Medical Biotechnology and Translational Medicine, Università degli Studi di Milano, via F.lli Cervi 93, 20090, Segrate (MI), Italy; roberta.gualtierotti@unimi.it.

DANISH, SUBHAN. Department of Soil Science, Faculty of Agricultural Sciences and Technology, Bahauddin Zakariya University, Multan, Punjab, Pakistan; sd96850@gmail.com.

GHIMPĂU, VALENTINA. University of Medicine and Pharmacy Craiova Doctoral School, 2 Petru Rares Str, Craiova, 200349, Romania; valentinaghimpau@gmail.com. 



\section{About the Series Editor}

MARTYN RITTMAN received his $\mathrm{PhD}$ in 2008 from the University of Warwick, UK followed by postdoctoral positions at the University of Reading, UK and the University of Freiburg, Germany. He joined MDPI as an editor in 2013. As Publishing Director, Dr. Rittman oversees several functions related to journal development and has a keen interest in open research, including preprints. 



\section{Preface to "Judging Research: How Should Research and Researchers Be Evaluated and Rewarded?"}

For this year's MDPI Writing Prize the theme was: "Judging research: How should research and researchers be evaluated and rewarded?" This book collects together the majority of entries we received. While the first six were awarded a prize, all of them contain thought-provoking content. The essays showcase the voices of young researchers from a broad range of countries and disciplines and will be of interest to anyone participating in research and its evaluation.

The essays cover a range of themes. Metrics, particularly citations metrics, feature prominently. Few were satisfied with the status quo and there are a number of creative suggestions for how they could be supplemented and improved, especially in a world where data analysis methods open the door to more complex and varied evaluation.

Incentives and motivation, including perverse incentives, are another broad theme covered by a number of the pieces. "Researchers want to do research" is the plea from Nilsson's colleagues in the essay awarded first prize. Other essays delve into whether current reward systems are driving issues with reproducibility or causing researchers to be dishonest, and how good incentives can promote good research as well as work-life balance.

Researchers are by their nature creative, restless, and inquisitive. I encourage the reader to explore the essays here with an open mind to envisage a future different from the present: a number of realistic and plausible scenarios can be found in the following pages. I am extremely grateful for all of the submissions and the time and effort of the authors. It was a genuine pleasure to read them and a truly difficult task to reward only a few.

The essays as presented have been lightly edited. This means that there may remain minor issues with grammar or expression. In addition, comprehensive fact-checking has not been carried out. We wish to present the thoughts of the early-career researchers in as unfiltered a way as possible, through their own voice and expression. The pieces here should be considered as a collection of authentic and original opinion pieces.

I am grateful to the support of the MDPI team members who have supported running the prize, in particular Dr Charlotte Dixon who assisted in screening submissions. A big thanks goes also to the MDPI Books team who have helped to prepare this volume. 



\title{
1 Incentives, Rewards, and Recognition - What Really Motivates a Researcher?
}

\author{
Nils A. Nilsson
}

The deadline for the big grant proposals are almost upon us, and throughout the corridors of the different departments everything seems normal, at first glance. However, a closer inspection reveals tired faces, slumped postures, and nervous chatter around the coffee machine. It is easy to understand why. Being awarded a large grant paves the way for years to come. It allows you to hire students and postdocs and to purchase equipment. It also makes it easier to get the next grant you apply for. But perhaps the grant system is not the best way to reward researchers with seemingly good ideas?

When starting to write this essay, I asked a few researchers what kind of reward system would motivate them the most. The most important reply that I received was both the most obvious and the most startling: "Just make sure that we're happy". This can mean a lot of things, but to the people I asked, it meant that researchers want to do research. If you take away unnecessary admin work, the worry about finding the next temporary position, and the enormous task of writing research proposals, generally good science follows. In the end, a scientist is no different from an entrepreneur or a software engineer. With all the basic necessities covered, good business and good code will follow.

That is not to say that good science should not be rewarded. My institute has an annual prize for the three most productive graduate students. This is a nice gesture and it makes us feel appreciated. According to research, this is actually of crucial import. It has been shown that public recognition makes workers feel more appreciated than a cash prize [1]. However, it seems that this kind of recognition is rare in academia, as is the more mundane yearly bonus. This brings me back to research grants. They are, in a way, a reward for a good track record and good ideas. But does it really work? In fact, studies suggest that whatever the incentive, be it gold stars, good grades, or pizza, dangling rewards in front of people seems to backfire more often than not $[2,3]$. Making the size of the reward contingent on how well the task was performed seems to be even worse, making workers cut corners and only focus on the pot of gold at the end of the road [4].

In the end, the hollow-eyed assistant professor and the sleep-deprived graduate student huddling in the corner by the coffee machine are only human. Academia is not intrinsically different from any other field or business, so if we are to be rewarded 
for doing a good job, do it smart. Start by making sure that we are paid enough, that we are taking time off, and give us enough stability to start families. This would be the greatest reward any researcher could receive.

That is not to say that scientists should be without expectations to perform. As in any job, there should be clear demands and responsibilities. The question of how to evaluate researchers is a hard one and requires careful thought. There are an array of metrics to go by. Publications, impact factors, citations, and Hirsch indexes all attempt to quantify research output. In one sense, it works. Highly successful researchers with many years of experience will have an easier time to land a new grant than someone with fewer accomplishments. But this is accurate only if the competition consists of scientists with roughly the same amount of experience. An early-career researcher will be hard-pressed to win against a professor with decades of citations under their belt. A better way to evaluate these people might be to use a normalised index. In Kreiman and Maunsell [5] suggest just that, a metric normalised by discipline, career stage, number of authors, and the like. This kind of metric would foster an environment which emphasises quality over quantity and would greatly improve the chances of a young researcher with new ideas and skills to win grants. It would be an improvement but not a complete solution, as there is also another side of the coin; what are they being evaluated for? The important factors will differ depending on whether it is a postdoctoral position, a professorship, a grant, or a prize. Therefore, there is no clear-cut solution. However, a big step forward would be to stop simply looking at number of papers and citations and instead implement a normalised system as suggested in Kreiman and Maunsell [5].

In conclusion, my answer for how to reward scientists is not "don' $t$ ". It is simply to do it smart. Start from the bottom of the pyramid of needs and provide stability for researchers to carry out their work in peace. If the department wants to praise scientists, they should do it in a public way and not simply with cash bonuses. In the end, something so simple as making the coffee free may have a big impact on how researchers feel about their role as scientists. Good science will follow.

\section{References}

1. Thibault-Landry, A.; Schweyer, A.; Whillans, A.V. Winning the War for Talent: Modern Motivational Methods for Attracting and Retaining Employees. Compens. Benefits Rev. 2017, 49, 230-246.

2. Kohn, A. Punished by Rewards The Trouble with Gold Stars, Incentive Plans, A's, Praise, and Other Bribes; Houghton Mifflin: Boston, MA, USA, 1993/1999/2018. 
3. Hur, J.D.; Nordgren, L.F. Paying for Performance: Performance Incentives Increase Desire for the Reward Object. J. Person. Soc. Psychol. 2016, 111, 301-316.

4. Chubb, J.; Watermeyer, R. Artifice or integrity in the marketization of research impact? Investigating the moral economy of (pathways to) impact statements within research funding proposals in the UK and Australia. Stud. High. Educ. 2017, 42, 2360-2372.

5. Kreiman, G.; Maunsell, J.H. Nine criteria for a measure of scientific output. Front. Comput. Neurosci. 2011, 5, 48. doi:10.3389/fncom.2011.00048.

(C) 2020 by the authors. Licensee MDPI, Basel, Switzerland. This article is an open access article distributed under the terms and conditions of the Creative Commons Attribution (CC BY) license (http://creativecommons.org/licenses/by/4.0/). 


\section{How to Evaluate and Reward Science and Technology Researchers}

\section{Qi Zhang}

Science and technology rewards are social incentive systems that inspire the creativity and enthusiasm of science and technology researchers and further promote the advancement of science and technology [1]. The first problem to be solved for the achievements of science and technology workers is how to scientifically and impartially evaluate the contribution of scientific and technological researchers. "The phenomenon of poor talent and inaccurate evaluation is extremely easy to dampen the enthusiasm of talents, affecting the creativity of talents, and even becoming a shackle for talent development." said by $\mathrm{Wu}, \mathrm{J}$. , the former dean of the China Academy of Personnel Science [2].

According to the Survey Report on the Status of Science and Technology Researchers [3], the scientific and technological researchers' recognition of the current science and technology evaluation reward system is not high, but the classification evaluation system with peer evaluation as the main body and comprehensively reflecting the professional characteristics and scientific and technological performance is full of expectations. Wang, G. [4], pointed out that to deepen the reform of the science and technology system and establish a more complete evaluation and reward system, firstly we must improve the talent evaluation standards and change the practice of evaluating talents by papers, projects, funds, and patents; in terms of evaluation, it is necessary to focus on the quality and actual contribution of scientific and technological innovation according to the characteristics of different types of scientific and technological activities, and formulate evaluation criteria and methods with clear orientation and equal emphasis on incentives and constraints; in terms of rewards, it is necessary to reform and improve the national science and technology reward system, and establish a scientific and technological reward mechanism with public nomination, scientific appraisal, practice testing, and high credibility [4].

I am an experimental technician and graduate of a Ph.D. degree at Shandong University, thus, taking the evaluation and rewards of engineering/experimental technicians in university as an example, how to evaluate and reward them is briefly talked about as follows.

First of all, there is an old saying in China that there are 365 industries, and each industry has a champion. There is a big gap between different industries, 
and it is difficult to unify the results and evaluation criteria. Therefore, as shown in Figure 1, different evaluation systems should be set up according to different positions, such as teachers, engineers, laboratories, and technicians. They should be configured differently in the evaluation system consisting of papers, patents, books, new technology or products, and soft science reports, to which different proportions are assigned. For example, unlike teachers who emphasize the evaluation of representative papers, engineers and technicians emphasize the development and application of new technologies and new products, followed by patents, and then, papers and works. According to the survey [3], the proportion of the engineering/experimental technicians surveyed who valued the different evaluation indicators is shown in Table 1.

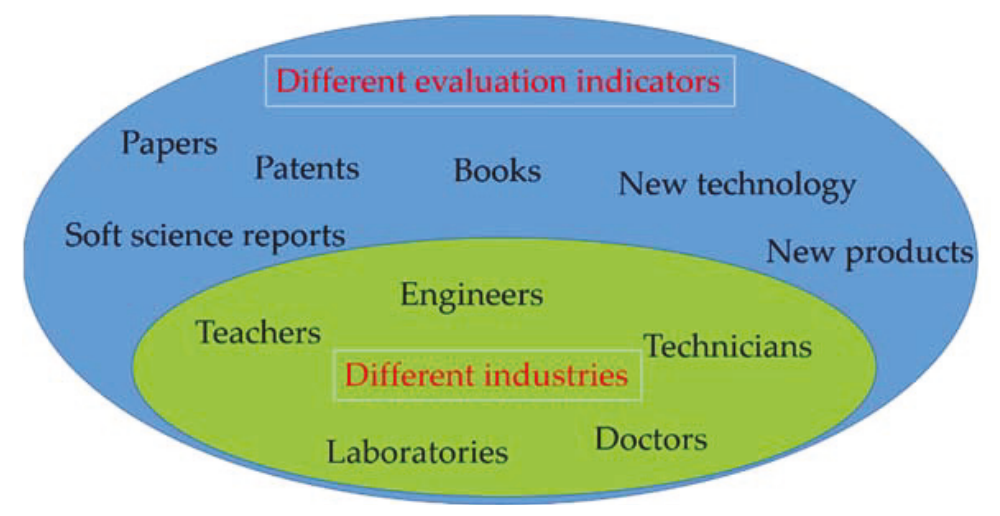

Figure 1. Different industries and different evaluation indicators.

Table 1. The proportion of the different evaluation indicators valued by engineering/experimental technicians *

\begin{tabular}{cc}
\hline Evaluation indicator & Proportion \\
\hline new technology or products & $60.7 \%$ \\
patents & $18.7 \%$ \\
papers & $12.5 \%$ \\
books & $3.9 \%$ \\
soft science reports & $1.1 \%$ \\
\hline
\end{tabular}

Secondly, in the evaluation standards of excellent science and technology researchers, "peer review" is the most important criterion. The higher the academic 
qualifications, the higher the professional titles, and the more participating in activities in research and development (R\&D), the higher the emphasis on peer review. Therefore, it is necessary to strengthen the supervision of the peer review process and results and ensure the impartiality and authority of the peer review.

Thirdly, different countries and regions have different levels of development. The industries and research fields that the state supports are also very different. Therefore, it is necessary to set up an incentive plan and evaluation system according to the national conditions.

Finally, evaluation and rewards are just a means of motivation for researchers. The advancement of technology will not be stagnant because of the existence or reasonableness of evaluation and reward, because the promotion of scientific and technological progress is the inherent goal of science and technology researchers.

Of course, science and technology researchers, for the sake of our legitimate and reasonable interests and rewards, we should also actively participate in the activities of evaluation and reward reform, and actively provide reform opinions and measures to jointly promote social progress.

\section{References}

1. Zhang, X. Scientific and impartiality of science and technology award assessment methods. China Awards Sci. Technol. 1998, 2, 7-9.

2. Luo, X. Talent evaluation, how to evaluate well and accurately. Guangming Daily, 22 July 2018, 07.

3. China Science and Technology Coordination Research and Propaganda Department, China Association for Science and Technology Development Research Center. The Third National Survey Report on the Status of Science and Technology Researchers; China Science and Technology Press: Beijing, China, 2014.

4. Wan, G. Deepen the reform of the science and technology system and establish a more complete evaluation system and reward system. Chin. Univ. Technol. Transf. 2012, 8, 79-80.

(C) 2020 by the authors. Licensee MDPI, Basel, Switzerland. This article is an open access article distributed under the terms and conditions of the Creative Commons Attribution (CC BY) license (http://creativecommons.org/licenses/by/4.0/). 


\section{Scientific Metrics: How Useful Are They?}

\section{Igor Ogashawara}

According to the scientific method, the final product should be the publication of the results and findings after testing a hypothesis. Therefore, several scientific metrics are based on the quality or quantity of these scientific products. While the pressure for results is common within the academic community, early career researchers are constantly worried about their metrics and publications for their job application. However, it is not clear how the hiring committee will judge the quality of the researcher and the respective work. For example, it is common to see positions in which the evaluation will be based solely on the number of publications. This system of evaluation promotes the academic culture of "publish or perish", which unfortunately affects the quality of the research.

In Brazil, the scientific production is evaluated based on the journal in which it was published. To do that, a national classification of scientific journals is used to evaluate the quality of the journal and, consequently, the manuscript. However, this classification has been criticized among scientists [1] and in the mainstream media [2]. The main critique is that the system is based solely on the impact factor of the journals, which may not represent the quality of the work, since a manuscript published in a low impact factor journal can be more influential than a manuscript published in a higher impact factor journal. Internationally, a similar criticism made the Research Gate Platform change the way that the RG Score was computed, since it was mostly based on the sum of the impact factor of all publications registered in the researcher's profile [3].

Another two important indices are the H-index and the H10-index, which have been used in several online academic platforms. They are based on the personal number of citations from one specific researcher and are not exempt of criticisms. For early career researchers, these indices are not so attractive, as due to the low number of publications and lower citation (since they are just starting to publish), they will have a lower score. Another problem of using these indices is related to the insertion of authors who did not collaborate with the manuscript. Therefore, it is an important initiative of some journals to now publish the division of labor at the end of the manuscript.

There is no perfect metric to evaluate a researcher or a study, so why do we care about them? 
For early career researchers, we care about them because they are used for evaluating our work. However, as with any index, these scientific metrics are not the best alternative to describe the quality of the researcher or the research. Nevertheless, I understand that it is not possible to deeply investigate all candidates for a position which may have hundreds of applicants. Therefore, these metrics could be used as an initial screening, however, it is important to select an index (or a set of indices) that can provide real information about the researcher. Unfortunately, it seems that early career researchers will have to worry about these metrics for a while, however, researchers (especially those that are part of a hiring committee) should focus on the indices that evaluate the individual manuscript and/or the individual researcher since those are the indices that will provide a better overview of the individual capacities. Additionally, it would be important to evaluate the contribution of the researcher in each manuscript, listed in the curriculum, which may be easier to quantify in the future since more and more journals are adding the contribution division of each author in the manuscript. Maybe in the future, with the integration of different platforms like Google Scholar, Mendeley, ORCID, Publons, Research Gate and Research ID, it will be possible to fairly evaluate the scientific work of a researcher. Until then, we will have to learn how to deal with the current scientific metrics and try to make the best of it.

\section{References}

1. Rocha e Silva, M. O Novo Qualis, que não tem nada a ver com a ciência do Brasil: carta aberta ao presidente da CAPES. Clinics 2009, 64, 721-724.

2. Ranking coloca revistas científicas brasileiras em 'risco de extinção'. O Estado de São Paulo 2009, A13. Available online: https:/ / emais.estadao.com.br/noticias/geral,rankingcoloca-revistas-cientificas-brasileiras-em-risco-de-extincao,398294.

3. Jordan, K. Exploring the ResearchGate score as an academic metric: Reflections and implications for practice. Quantifying and Analysing Scholarly Communication on the Web (ASCW'15) 2015. Available online: http://ascw.know-center.tugraz.at/wp-content/ uploads/2015/06/ASCW15_jordan_response_kraker-lex.pdf.

(C) 2020 by the authors. Licensee MDPI, Basel, Switzerland. This article is an open access article distributed under the terms and conditions of the Creative Commons Attribution (CC BY) license (http://creativecommons.org/licenses/by/4.0/). 


\section{Tangible and Non-Tangible Rewards- a Balancing Act}

\section{Magaret Sivapragasam}

Maslow's hierarchy of Needs [1] lists down the theory of personality that identifies five basic human needs categories which are: physiological needs, safety needs, social needs, esteem needs, and self-actualization needs. Regarding evaluation and rewards, Maslow noted the following: "Esteem needs include the need for things that reflect on personal worth, self-respect and social recognition. Individuals need to attain a good reputation in a group or strive to increase their status in the eyes of others are driven by these needs. The organization can help to satisfy employees' esteem needs by showing workers that their work is appreciated and recognized." He further iterates that esteem needs are important for personal growth and fulfilment.

This resonates well in the life of a researcher. The life of a researcher is indeed a juggling act. It involves one of experimentation, applying for grants, preparing manuscripts, teaching, student supervision and many others. Often, we find many researchers' asking this question, "What is in it for me?" As a postdoctoral researcher myself, I have been often a victim of lack of reward when it comes to research. Institutions are mainstream when it comes to merit systems, often giving credit to achievements that benefit the university rather than the individual. These include (depending on the institution), the number of journals published as the main author, rating/impact factor of journals, number and value of grants obtained and others. Sadly, more and more academics are tailoring their research outcomes and scholarly publications to fit the universities' evaluation criteria. No attention is paid to writing a popular article, doing a radio interview, speaking at a "science café" or tweeting about one's research findings. Is not the ultimate goal of science, dissemination? For research to make an impact, it must be shared with the public. One such method to do so is to encourage open access publications. Institutions should provide funds based on a merit system for researchers to publish in open access journals. In addition to that, institutions can adopt a varied metric, such as rewarding publications (other than journals), such as newspaper articles and other non-traditional media coverage, as media visibility can boost research within the scientific community. Awards that are based on excelling in doing both research and publicly sharing the study with the public should be made more apparent. Trainings like these can be bolstered by having annual prizes that reward scientists who combine and excel both in research and communicating their research after publication. 
Recognitions (cash or non-cash) serve as a good measure of reward. While cash-based recognitions are straight forward, non-cash recognitions are a cheaper alternative to institutions to help celebrate a researchers' merits. These can include, verbal or written recognition (institution website/newsletter), celebratory meals, shopping vouchers and many others. Research should be rewarded and given its due credit. By doing so, it will encourage younger researchers to be motivated and follow through exemplary leads.

Training and developmental programmes are also an important aspect of providing reward to researchers' and I believe that every organization should find it decisively important to invest in people. Rewards in forms of training should also be incorporated in merit systems for researchers. Training programmes such as these increase the researcher's self-efficacy, which inevitably pushes their performance levels. It also bridges the gap between employees' work practices and their work environment. Institutions that invest in training programs also make employees feel indebted to their organizations. When a researcher gets the vibe that the organization is willing to spend money on their career development, it gives them the confidence in being indispensable, in turn, leading to the employee maximizing output at work.

\section{"No one should approach the temple of science with the soul of a money changer." -Thomas Browne}

From 48 B.C, money changers have been historically labelled to be the cause of increased taxes and even causing corruption in the Roman empire. This quote by Thomas Browne identifies the linking of the concept of science to that of a money changer. Interestingly, he urges us to not have a sense of greed and loathing when it comes to science. Being a researcher myself, at times I do feel demotivated and at the verge of giving up. We all need a little motivation at times-just to let us know that the organization/university appreciates us and the work we do. However, the use of payment as an 'incentive' to participate is controversial.

The common currency of rewards for a job is salary. Salaries are the most significant and motivating benefit that is received (in return) for executing a service. Without a doubt, salaries are the most important factor that motivates individuals to go out and seek work. While salaries refer to a tangible reward system, intangible rewards are those of learning, development and work experience. Examples of these include opportunity to develop, recognition from the employer and colleagues and personal achievement. The aim of a total reward system is to maximize the positive impact that a wide range of rewards can have on motivation, job engagement and organizational commitments. Rewards for research and researchers can be both 
tangible and non-tangible. Institutions just need to find the appropriate system that works best for the employer and employee. It is all in the balance!

\section{Reference}

1. McLeod, S. Maslow's hierarchy of needs. Simply Psychol. 2007, 1.

(C) 2020 by the authors. Licensee MDPI, Basel, Switzerland. This article is an open access article distributed under the terms and conditions of the Creative Commons Attribution (CC BY) license (http://creativecommons.org/licenses/by/4.0/). 


\section{Judging and Rewarding Research and Researchers: Beyond Bibliometrics}

\section{Arvind Sharma}

Contemporary evaluation of researchers and research is based on the number of publications, impact factors of the publications, h-index, RG scores and citation index, respectively. Statistically, these parameters rate the performance of research and researchers, but the quality of research might suffer in the race for these "bibliometrics" [1]. This affects the innovativeness of the researchers.

Critically, research must be evaluated on novelty, the robustness of methodology, appropriateness of statistical methods and advancement of the current body of knowledge. Research should have uniqueness, objectivity and validity. There are frequent instances of repetitive research where only the location and researchers change, whereas the content remains the same. This is a waste of time, resources and funds. This research is bereft of originality and objectivity. In light of the current scenario of the paucity of research funds, funding mechanisms need revisiting where innovativeness, societal impact, quality of science and long term benefits of research should be the new paradigms of research funding. Research must have wider applicability across disciplines and across geographical borders, instead of building islands of excellence.

The evaluation of research across disciplines based on the "bibliometrics" can be flawed. Medicine and bioengineering sciences might attract more researchers, publications, grants, and funding. The impact of other disciplines might suffer from the lack of popular interest in the contemporary context but their long term value cannot be evaluated through the current criteria. Research done in the developing world is conducted under difficult conditions due to lack of infrastructure, funding, mentorship and organizational structure. But this research might be more feasible, needful, applicable and impactful. It should be encouraged and recognized through collaborations and capacity building to improve competencies. This will foster global teamwork, breaking geographical and intellectual barriers. Similarly, researchers in the developing world are not able to publish in high impact journals due to publications costs, connectivity and accessibility to library resources. Research published in open access resources should be given high weightage provided it is subjected to intensive content-based peer review. Research evaluation must check 
and discourage publication in predatory journals, which are undermining original and creative research.

Researchers should be evaluated on the originality and novelty of their research. The consistency shown by a researcher in communicating his research through publications over a period of time is an important criterion of evaluation. The body of work created by a researcher over a period of time that has moved the research field forwards must be a criterion for evaluation. Collaborative spirit in research through building interdisciplinary teams and group efforts reveal the people skills of the researchers. This team spirit across countries and continents, which synergizes the core competencies of each team member, making research more impactful, should be a factor in the evaluation. Research methodology must be explicit and data disclosure must be made mandatory followed by open access to the peer review process post-publication. These steps will improve the objectivity of evaluation of the scientific contribution, the prowess of researchers and discourage redundant research. Conflict of interests in research should be a criterion in the evaluation process. Overemphasis on publications can affect the success of young researchers in winning research grants even if their research proposals have fresh ideas and new techniques as late-stage researchers will be unfairly advantaged.

Researchers' contributions to the society and community in the form of reviewers for journals, research supervision, field work, and community outreach should contribute to the evaluation process. Communicating science to the society makes the society more aware and enlightened, leading to indirect benefits to mankind. Public engagement makes research more meaningful and can open fresh perspectives and ideas for research. Publishing popular articles and policy documents should be credited. Risk-taking abilities in research, as well as reporting of negative results, should be recognized to encourage innovation.

Research should be rewarded through increased and extra funding to carry forward the body of work in the realms of innovation and improvement. The geographical spread of the research to build new teams should be a reward. Researchers spend the prime of their youth in their laboratories and fields in the quest for intellectual satisfaction. Good researchers must be financially rewarded so that finances never remain a concern to distract them from the path of research excellence. Rewarding scientists for the work that bring changes in society bridges the gap between science and society. The personal satisfaction and societal recognition is in itself a reward. Public communications by researchers must be rewarded financially as it helps to attract new students to research, impress funding bodies, building research networks and fostering new collaborations. Researchers should be given 
wide media publicity, especially on social media. It boosts their self-esteem and ensures government and industry support for the research institutions.

Scholarships and endowments in the name of researchers in high schools and colleges is a way of recognition and stimulating research temper in the next generation. Frameworks need to be built to assess impact assessments of research done by researchers that should be given more weight in the evaluation process. This approach will explicitly document impacts and will be endorsed by the funding agencies, leading to recognition and prestige. This will further help researchers to anticipate and establish research partnerships for higher impact studies [2]. Societal impact evaluation of research and researchers will make their connections with industry and funding bodies clearer, goal-oriented and more applicable. This will further improve the evaluation process. Travel grants for collaborations, improving skills and for the strengthening of laboratories can be other ways of recognition.

Evaluation and reward criteria for research and researchers needs to change in the context of changing funding patterns for research, higher attrition rates of researchers from academia to industry and increased public awareness.

\section{References}

1. Hicks, D.; Wouters, P.; Waltman, L.; De Rijcke, S.; Rafols, I. Bibliometrics: The Leiden Manifesto for research metrics. Nat. News 2015, 520, 429.

2. Reward research that changes society. Nature 2018, 553, 5. doi:10.1038/d41586-017-08943-6.

(C) 2020 by the authors. Licensee MDPI, Basel, Switzerland. This article is an open access article distributed under the terms and conditions of the Creative Commons Attribution (CC BY) license (http://creativecommons.org/licenses/by/4.0/). 


\title{
6 Judging Research in the Doors of Irreproducibility Crisis Era
}

\author{
José L. Flores-Guerrero
}

"Numbers do not exist outside our brains, and even there, inside, they only exist at the conceptual level, and not at the physiological level. In the real world we can see 3 books, in a fictional universe we could see 3 UFOs.

But who ever saw a 3, a simple 3?"

Mario Bunge [1]

Researchers, since the beginning of their careers have being focussing their attention on a particular number, 0.05. The desired threshold of statistical significance. Several millions of published research articles rely on the capability of this number, to support their conclusions. Interestingly, such statistical measure have little to say about the reproducibility of the reported findings [2]. This fact may raise questions about how research should be judge and how researchers should be evaluated, given that reproducibility is key for the scientific method, and it seems that it is in crisis.

In 2015, the Open Science Collaboration reported an attempt to replicate about 100 experiments published in three academic psychology journals. The results of this attempt of replication showed that only $36 \%$ of the studies remained significant after a replication trial [3].

Furthermore, there is a continuous debate about the reliability of the research in the medical field. Begley and Ellis reported that oncological have a low reproducibility rate of $11 \%$ [4]. However, these results are not limited to the field of psychology or medical sciences. According to Monya Baker, $90 \%$ of a sample of 1576 researchers from different fields, referred that there is a crisis of reproducibility in science. As well, 70\% of them also affirmed that they did not succeed to reproduce the results reported by their peers [5].

Such numbers support the idea that there is a reproducibility crisis undergoing in modern science.

There are a number of reasons of why there is such a widespread inability to reproduce experimental results. In the second part of this essay, I will describe how the way research is judge and the way researchers are rewarded since their very early stage, represent an important cause of such reproducibility crisis. 


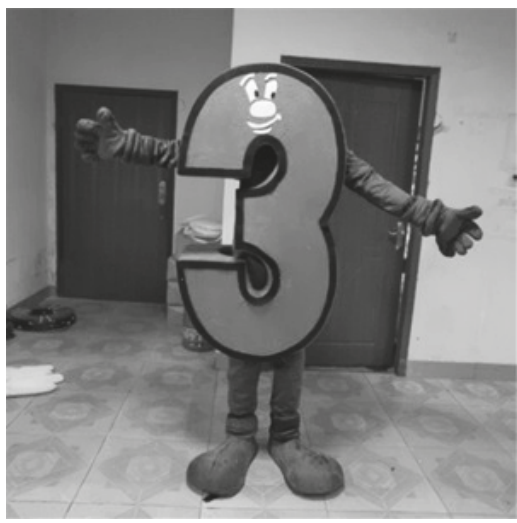

Figure 1. Bunge's nightmare.

\section{The "publish or perish" culture}

The pressure to publish the greatest amount of content is not an abstract or undeclared force; it is direct and explicit. A minimum or desirable number of publications per year are stablished in research departments throughout the academic world. Following such recommendations are fundamental to keep a position on academia and build an academic reputation.

Consequently, as any other system based on quotas, some people try to find a "the shortest way" to the goal. Some attach their names to work with which they have little to do. Moreover, this phenomenon has given rise to predatory journals that are willing to publish any article, regardless of the rigor with which the research was conducted, with the sole condition of covering the payment. In the worst case, some researchers have come to falsify their data to obtain a result that is publishable.

The rise of predatory journal, can even be considered as a crisis by itself, but it is important to consider it as an extension of the original problem. The popularity of such predatory journals, as a solution to publish as many articles as necessary, implies ethical issues, such as the misuse of founding to pay such publications fees. The articles published in predatory journals become unlikely to be used to build the background of future research.

This phenomenon was investigated by Bagues and colleagues. They found that only $38 \%$ of these journals have published at least 5 articles that have received at least 5 citations in a period of 5 years, even after including self-citations [6]!

It seems that as many other crises, the reproducibility crisis, has as a common root the incentives that have been established for researched. Despite the fact that 
such system have a reasonable justification, it seems that it has a limit, perhaps the 30 million citations (until July 25th, 2019) in PUBMED, could be though as such limit.

Therefore, it is necessary to modify the way research is evaluated, for instance, by requesting more solid statistic treatment of the data, upgrading the statistical threshold, or requesting a complementary approach to frequentist statistics, such as Bayesian statistic approach. Nonetheless, as researchers are in the center of research, and not the other way around, the scientific community should propose a more collaborative approach and long term goals, therefore, the yearly productivity, would no be longer the center of attention of researchers.

Consequently, researchers will have the time to work and lately, report, probably under the name of relatively big groups of researchers, studies that already show a high level of replicability and clinical relevance; in such scenario, the number 0.05 will lose its magic power.

In conclusion, there is a crisis of replication in science. And this is caused, at least in part, by the publishing pressure, which way is paved by the system of research reward.

There are different methodological alternatives to solve the reproducibility issue, but the key step is to recognize the deficiencies on the current system and to train future researchers with high ethical standards, in order to use their potential to solve real world problems. As the Noble Laurate Françoise Barré-Sinoussi said. "We are not making science for science. We are making science for the benefit of humanity."

\section{References}

1. Bunge, M. Science, its method and its philosophy. Siglo XX 1978, 110.

2. Benjamin, D.J.; Berger, J.O.; Johannesson, M.; Nosek, B.A.; Wagenmakers, E.J.; Berk, R.; Bollen, K.A.; Brembs, B.; Brown, L.; Camerer, C.; et al. Redefine statistical significance. Nat. Hum. Behav. 2018, 2, 6-10.

3. Open Science Collaboration OS. Estimating the reproducibility of psychological science. Science 2015, 349, aac4716.

4. Begley, C.G.; Ellis, L.M. Raise standards for preclinical cancer research. Nature 2012, 483, 531-533.

5. Baker, M. 1,500 scientists lift the lid on reproducibility. Nature 2016, 533, 452-454.

6. Bagues, M.; Sylos-Labini, M.; Zinovyeva, N. A walk on the wild side: 'Predatory' journals and information asymmetries in scientific evaluations. Res. Policy 2019, 48, 462-477.

(C) 2020 by the authors. Licensee MDPI, Basel, Switzerland. This article is an open access article distributed under the terms and conditions of the Creative Commons Attribution (CC BY) license (http://creativecommons.org/licenses/by/4.0/). 


\title{
7 Should the Quality of the Journal Determine the Quality of the Research?
}

\author{
Ahmet Yüksek
}

Although there are many different ways to explain the results of scientific research, the most important and effective way is still publication in scientific journals. Academic journal publishers or scientific organizations publish these research results that have been reviewed and verified by experts in the field. It is essential to understand and measure the importance, quality and impact of these publications, whether for scientists or for organizations that hire or provide financial support. For an academic researcher, problems begin here.

Even if a researcher has done a very successful academic study without financial support, it is problematic as science needs serious financial support to announce it and even if this study is published in a journal, it will be considered as good or poor according to previous articles in that journal because of the impact factor.

After this point, the evaluation of the publication is according to the citation rate received. Still no assessment is made by experts in the field. Even if this assessment is made, objectivity will be discussed. It is also a distressing fact that readers have to pay for some journals, no matter how high quality your research is in the field of academic publishing, which has become a market.

A widely used criterion in the evaluation of scientific publications is the Journal Impact factor [1]. As the impact factor increases, the concept that the journal is read more and, therefore, higher "quality" is established. The impact factor is a criterion regarding the citation rate of articles in the journal. However, it is controversial that many attributed publications contribute more to science. It is also not possible to measure unnecessary references to each other's articles. There may be publications with more or less citations in a journal, or publications with very few citations in a journal with a high impact factor. In this highly inconsistent environment, it does not seem meaningful to argue that all publications in journals with high impact factors are of high quality.

In 2012, the Declaration on Research Assessment (DORA) was published in San Francisco [2].

The purpose of the DORA is to improve the ways in which the outputs of scholarly research are evaluated. This declaration emphasizes the following; do not use journal-based criteria in any assignment, promotion and funding process, and conduct research evaluations only on the work or results, not on the journal. 
Indeed, it is difficult to evaluate researchers on a publication basis. The $\mathrm{H}$ index has been developed for this purpose [3]. J.E Hirsh emphasized that the $h$ index is superior to the impact factor of publications in the evaluation of researchers [4]. For this research, he examined the $h$ index values of the researchers who have received a Nobel prize in the last 20 years. He also emphasized that researchers with a high $h$ index should be closer to the Nobel Prize, as the Nobel award was given to the inventor who made a difference as a result of years of productivity. However, in the last 20 years, researchers found that the majority of the $h$ index values of the Nobel field researchers were between 35 and 39. According to this result, the $h$ index is not sufficient to measure how much the researcher contributes to science.

A successful researcher near the end of his career, in the last 5 years, may have an $h$ index value that is lower than a young researcher. This result should not conclude that the experienced researcher is less successful. Albert Einstein's $h$ index is 115 by Google scholar, while his $\mathrm{h}$ index in the last 5 years is 65 . Therefore, long-term and continuous success of a researcher should be considered as a criterion. The long-term $h$ index can be used in this field. However, increasing the $h$ index with inappropriate citations cannot be avoided [5].

It is not appropriate to use the number of citations in the evaluation unless the quality of the cited study is measured and, in this way, this process becomes increasingly complex.

There is more than one academic journal in one discipline in medicine. Most of them are published by big publishing houses. The most valuable articles for that discipline can be shared by the valuable referees of these journals on another platform. In today's world where printed journals are replaced by e-journals, large publishing houses can publish the 100 most valuable works of each year on their websites. In addition to the number of citations received by the manuscript in the evaluation, the submission by the referees to an open platform for other researchers and listing it there may provide a solution. Further announcement also positively affects the index $\mathrm{h}$ of the manuscript.

However, the process of evaluating academic publications is complex and neutrality is difficult to maintain due to many factors.

\section{References}

1. Claritive analytics İmpact Factor. Available online: https://clarivate.com/essays/ impact-factor/ (accessed on 21 July 2019).

2. San Francisco Declaration on Research Assessment (DORA). San Francisco, USA, 2012. Available online: https:/ /sfdora.org/read/ (accessed on 21 July 2019). 
Global Benefits of Open Research. The 2019 MDPI Writing Prize

3. van Haselen, R. The h-index: A new way of assessing the scientific impact of individual CAM authors. Complementary Ther. Med. 2007, 15, 225-227. doi:10.1016/j.ctim.2007.10.004.

4. Hirsh, J.E. An index to quantify an individual's scientific research output. Proc. Natl. Acad. Sci. USA 2005, 102, 16569-16572. Available online: https://doi.org/10.1073/pnas. 0507655102.

5. Available online: https://scholar.google.com.tr/citations?user=qc6CJjYAAAAJ\&hl=tr\& oi=ao (accessed on 20 July 2019).

(C) 2020 by the authors. Licensee MDPI, Basel, Switzerland. This article is an open access article distributed under the terms and conditions of the Creative Commons Attribution (CC BY) license (http://creativecommons.org/licenses/by/4.0/). 


\section{Judging Research: How Should Research and Researchers Be Evaluated and Rewarded?}

\section{Ajna Bihorac}

"Scientists, like all men and women, are opinionated, dogmatic, ideological" [1,2]. This can be considered as the main reason why procedural objectivity has to be followed [2]. Unfortunately, in reality, the objectivity is not considered as a precise representation of the reality and subjectivity is not about misrepresenting the reality. "The former always has been nothing more than a compliment paid to someone who happens to agree with you and the latter has never been more than a term reserved for those who say things you consider beside the point" [3].

It was always considered that doing the right things and performing them correctly were not adequate conditions for decent research, but were the necessary conditions etc.... In recent years, things have changed. Before 2000, there was the Science Citation Index on CD-ROM from the Institute for Scientific Information (ISI), used by scientists for an evaluation. Recently, to be more accurate, in 2005, Jorge Hirsch, proposed the h-index, promoting citation counting for individual researchers. Additionally, the preoccupation with the journal impact factor grew gradually after 1995 [4]. All this leading to belief that the quality of the scientific research is slowly declining, thus making it difficult to evaluate [5].

Efforts are made by some senior scientists to change the system that is slowly deteriorating. At the University Medical Centre Utrecht in the Netherlands, a new approach is implemented such as writing an essay about candidates' achievements without too much focus on the publications. Additionally, some scientists decided to nurture the philosophy of openness and risk taking, such as, taking the risk for research that has not been done previously even if it leads to huge failure [6]. Unfortunately, most of the research is unpublished or unavailable to scientists interested in it. Sharing the data in the open access repositories would be the way to fix that problem [7]. On the other hand, the data sharing can be shortened in the expression "the paradox of nefarious battles." This means that, although it is good for the scientists to share the unpublished data, the journals have a problem in publishing pre-released data, thus the environment of the competition is more present than the environment of the collaboration [6]. Finding a way to reward the 
team accomplishments can help scientists from the team to be more appreciated, even if they are not stated as the first author [7].

Achievement goal theory (AGT) is known as one of the most popular motivation theories in sport and physical activity [8,9]. In this theory, two fundamental goal orientations are recognised: task-involving and ego-involving. Task goals highlight learning and personal improvement, leading to expertise in the task. On the other hand, ego goals focus on the achievement of social recognition while outperforming others. Task goals are connected with intrinsic motivation, pleasure in activities, and belief that effort causes success, while ego goals describe higher cognitive anxiety, belief that ability causes success and low effort when a task is difficult. It has been shown that a task-involving climate has to be present for a longer period, thus having positive long-term effects. In contrast, a performance-oriented climate has instant effects on students' motivation, but can be observed as controlling and unsupportive, thus students do not acheive the goals and negative self-talk is triggered [9].

A lot of the things have to be changed for scientists to feel comfortable at their workplace and to be recognized for their success. Additionally, the positive approach should lead to a more honest attitude and better results. Besides recognizing the problem inside the scientific community, it should be discussed openly. The introduction of scientific research to the public can influence positive reactions from societies, thus leading to an increase in self-worth and attracting possible collaborators. "Although the collective efforts of funders, journals, and regulators will be critical, individual institutions will ultimately have to be the crucibles of innovation, serving as models for others. Institutions that monitor what they do and the changes that result would be powerful influencers of the shape of the collective scientific future" [10].

\section{References}

1. Kerlinger, F. Behavioral Research; Holt, Rinehart and Winston: New York, NY, USA, 1979.

2. Smith, J. Judging research quality: From certainty to contingency. Qual. Res. Sport Exerc. 2009, 1, 91-100, doi:10.1080/19398440902908928.

3. Rorty, R. Philosophy and the Mirror of Nature; Princeton University Press: Princeton, NJ, USA, 1979.

4. Hicks, D.; Wouters, P.; Waltman, L.; Rijcke, S.; Rafols, I. Bibliometrics: The Leiden Manifesto for research metrics. Nature 2015, 520, 429-431. doi:10.1038/520429a.

5. SEDL. What Are the Standards for Quality Research? Technical brief, 2005; Number 9.

6. METRICS. How to reward scientists for doing research that matters. 2016. Available online: https:/ / metrics.stanford.edu/research/how-reward-scientists-doing-researchmatters. 
7. Moher, D.; Naudet, F.; Cristea, I.A.; Miedema, F.; Ioannidis, J.P.A.; Goodman S.N. Assessing scientists for hiring, promotion, and tenure. PLoS Biol. 2018, 16, e2004089.

8. Roberts, G.C.; Treasure, D.C.; Conroy, D.E. Understanding the dynamics of motivation in sport and physical activity: An achievement goal interpretation. In Handbook of Sport Psychology; Tenenbaum, G., Eklund, R.C., Eds.; John Wiley: Hoboken, NJ, USA, 2007; pp. 3-30.

9. Marjanović, M.; Comoutos, N.; Papaioannou, A. The relationships between perceived motivational climate, achievement goals and self-talk in physical education: Testing the mediating role of achievement goals and self-talk. Motiv. Emot. 2019, 43, 592-609. doi:10.1007/s11031-019-09760-2.

10. Moher, D.; Naudet, F.; Cristea, I.A.; Miedema, F.; Ioannidis, J.P.; Goodman, S.N. New Principles for Assessing Scientists. Issues in Science and Technology 2018.

(C) 2020 by the authors. Licensee MDPI, Basel, Switzerland. This article is an open access article distributed under the terms and conditions of the Creative Commons Attribution (CC BY) license (http://creativecommons.org/licenses/by/4.0/). 


\section{Open Science, Sustainability and Qualitative Assessment of Merit for an Objective Evaluation of Research}

\section{Roberta Gualtierotti}

The evaluation of scientific research has changed over the last few decades. This is not only due to the introduction of innovative technologies such as the so-called multi-omics and the increasing awareness of the need of a personalized approach to healthcare [1], but also due to the growing consideration given to open science, which envisages open access publications, open data and open peer review [2]. However, different parameters should be evaluated in different research fields. Preclinical studies, even when dealing with primary cell cultures, should consider the differences of each individual such as sex, ethnicity and genetics. Translational medicine should be aimed at finding practical solutions for unsolved questions and unmet needs of patients, such as new therapeutic targets and novel biomarkers. The aims of clinical research in general should be feasible and practical, with socio-economic impact and, possibly, resource attraction from industry. Research aimed at implementing personalized medicine should be incentivized as it may provide more realistic disease models and efficient healthcare approaches. Ideally, pharmacoeconomic evaluations should be the foundation of each new study on pathogenic mechanisms and therapeutic targets, in order to demonstrate that research on that topic is useful. Another interesting concept is the sustainability of research [3]. Scientific research based on sustainable materials and methods should be encouraged, because it allows the reproducibility of the experiments and reduces the discrimination of low-income countries, thus contributing to a global dissemination of scientific knowledge.

In an open science environment, collaboration, transparency and accessibility of data contribute to worldwide scientific progress. Transparency should be evaluated based on preregistration of the aims and analysis plan before the beginning of a study and based on the accessibility of research materials, data and reports [2,4].

Stakeholder engagement is gaining considerable attention in research fields such as personalized medicine and guideline development and it should be positively evaluated.

As far as the value of a researcher is concerned, it should be evaluated based not only on the scientific production, but also based on merits and achievements. The h-index increases with the age of the researcher, even in the absence of new publications. Therefore, the evaluation of a researcher cannot be reduced to a number, 
because the career of a researcher is the result of a complex set of different variables. The well-known Hirsch (h) index [5] varies greatly from field to field and researchers have diverse "missions" and indicators may be based on the relevance to policy, industry or the public rather than on academic excellence [6]. Furthermore, the h-index is often distorted by other variables such as length of career, age of the researcher or time of publication of an article [6]. The use of multi-dimensional criteria based on the specific research field [7] or the use of adjusted indexes that consider age and career of the researcher [8,9] may represent alternative solutions.

In evaluating a researcher, also other skills should be considered, such as the capability of searching collaborations with national and international research groups, of coordinating team members with different specialties. Knowledge is the only resource that increases when used. Therefore, the ability of disseminating findings to different stakeholders, including politicians and public, in order to inform decision-making and spread knowledge should be rewarded. Finally, although the presence of a mentor is often important and sometimes fundamental in the career of a young scientist, researchers should demonstrate that they are independent, for example, by being first or last authors, at least in the latest publications.

More importance should be given to negative trials. Indeed, if well conducted, negative studies require as much effort as other studies with positive findings. Similarly, negative results may be relevant as they may prevent other researchers from a waste of time and resources on similar studies and may pave the way for future research.

Based on this profile, the best researchers should be rewarded for their commitment with job promotions and funding. It would be great if funding agencies and sponsors could collaborate with the Academy to co-fund tenured positions or support the development of a laboratory with a team of co-workers. Even then, researchers should be periodically re-assessed.

In conclusion, the quality of scientific production should be based not only on indexes and metrics, but also on a set of qualitative criteria such as the practical consequences of findings, the rational use of resources, the way of conducting studies and the integrity and transparency of researchers.

\section{References}

1. European Council Conclusion on personalised medicine for patients (2015/C 421/03).

2. Available online: http://ec.europa.eu/research/openscience/index.cfm?pg=home\& section=monitor. 
3. Franzen, S.R.P.; Chandler, C.; Siribaddana, S.; Atashili, J.; Angus, B.; Lang, T. Strategies for developing sustainable health research capacity in low and middle-income countries: A prospective, qualitative study investigating the barriers and enablers to locally led clinical trial conduct in Ethiopia, Cameroon and Sri Lanka. BMJ Open 2017, 7, e017246.

4. National Institutes of Health. 2014. Available online: https://web.archive.org/web/ 20161115161336/https:/ /obssr.od.nih.gov/2014/12.

5. Hirsch, J.E. An index to quantify an individual's scientific research output. Proc. Natl. Acad. Sci. USA 2005, 102, 16569-16572.

6. Hicks, D.; Wouters, P.; Waltman, L.; de Rijcke, S.; Rafols, I. Bibliometrics: The Leiden Manifesto for research metrics. Nature 2015, 520, 429-431.

7. Mårtensson, P.; Fors, U.; Wallin, S.-B.; Zander, U.; Nilssone, G.-H. Evaluating research: A multidisciplinary approach to assessing research practice and quality. Res. Policy 2016, 45, 593-603.

8. Sidiropoulos, A.; Katsaros, D.; Manolopoulos, Y. Generalized Hirsch h-index for disclosing latent facts in citation networks. Scientometrics 2007, 72, 253.

9. Harzing, A.W.; Alakangas, S.; Adams, D. hIa: An individual annual h-index to accommodate disciplinary and career length differences. Scientometrics 2014, 99, 811.

(C) 2020 by the authors. Licensee MDPI, Basel, Switzerland. This article is an open access article distributed under the terms and conditions of the Creative Commons Attribution (CC BY) license (http://creativecommons.org/licenses/by/4.0/). 


\section{Impact Factor $\neq$ Impact: Lessons Learned from Research Evaluation}

\section{Luca D. Bertzbach}

Imagine, the most recommended biomedical research paper of the Faculty of 1000 would describe a fancy CRISPR-mediated technology leading to non-human primates that are fully resistant to multiple hereditary cancers. Unsurprisingly, the publishing journal has a stratosphere-high impact factor, an SJR score of 18.52 and an Eigenfactor ${ }^{\circledR}$ score of 0.332 ... Furthermore, the senior author's research metrics suggest he is nothing short of a genius with an h-index of 77, an RG score of 49.2, an i10-index of 427, >500 connections on LinkedIn, and about half a million followers on Twitter. Their future research gets mega funding and others build their laboratories based on this outstanding work. However, after years of research and millions invested, it later turns out that a huge proportion of the non-human primate paper was fundamentally flawed. Quo vadis, research evaluation?

People have tried to evaluate research and researchers for decades and it is widely agreed that this evaluation should aim at (i) assessing the relevance, efficiency and effectiveness of research projects and (ii) evaluate the scientific contribution of individual researchers. Here, the evaluation of individual researchers optimally serves as a means of assessing their ability to conduct research or to fund their future work-based on their past performance. However, this has always been extremely challenging for those who evaluate research, especially in terms of evaluating potential impact. In part, this is because it gets very complicated to evaluate "real world impact", i.e., impact beyond academia [1]. Moreover, evaluation is often biased since evaluation of researchers is mostly limited by the number of published papers and by the number of citations received [2]. Decades after Science published the concept of journal impact factors [3], this basis of evaluation remains a commonly used proxy for the quality of a scientific article and of a researcher's scientific output. It very often still dictates the choice of where to submit a paper (with prestige of the respective publisher or journal playing a very important role). Until now, those metrics strongly influence a researcher's or funding agency's decision whether or not research can be considered as sound and solid or questionable and dodgy. While it is tempting to boil down complex statistics and evaluations into a single index number, the use of easily quantifiable indicators such as the journal impact factors, the h-index, or similar metrics is too simple and can lead to false assumptions. 
"It is common, and encouraged by many journals, for research to be judged by the impact factor of the journal that publishes it. But as a journal's score is an average, it says little about the quality of any individual piece of research."

Randy W. Shekman

What does the future hold...? Maybe we implement an intelligent combination of advanced metrics and rely on qualitative measures in order to decrease the sexiness of the so-called "smallest publishable unit" and withstand the "publish or perish"-downward spiral. Something like the h-index divided by age or by career-years and only compared to researchers who work in the respective field could be an idea. Researchers should choose their journals wisely according to cost and speed of the publication process and visibility of their work rather than journal impact factors. To date, the majority of online open access journals unfortunately cannot compete with established publishers, mainly because of questions regarding the perceived quality and acceptance of online open access publications [4]. Moreover, as one of the loopholes of academic publishing, predatory journals pose a serious threat to science integrity [5]. These issues nicely illustrate the enormous challenge of unbiased research evaluation and unequivocally emphasize the need for action.

To answer the question of how research and researchers should be evaluated and rewarded, the system requires refinement. A break with publishing traditions, goal-oriented student and post-doc education towards better science communication, a more transparent peer-review process and concepts like the "publish first, curate second" approach [6] proposed by online open access advocates will undoubtedly be baby steps in the right direction. In addition, a focus on team science (spanning boarders and different specialties), the potential of a researcher or a group of researchers to attract funding, and funding of exciting and challenging interdisciplinary efforts that improves common knowledge in the long run should be the premise for funding agencies.

But... what's actually next? One of the biggest publishers could soon launch the Journal of $p>0.05$ to broaden its scope. Doug Zongker's paper "Chicken Chicken Chicken: Chicken Chicken" [7] could finally get retracted (for what reason exactly...?). A group of scientists could pull off a cunning hoax that makes it into news feeds worldwide as yet another example of 'real' fake research in peer-reviewed journals. Way to go, "research evaluation".

\section{References}

1. Penfield, T.; Baker, M.J.; Scoble, R.; Wykes, M.C. Assessment, evaluations, and definitions of research impact: A review. Res. Eval. 2014, 23, 21-32. 
2. Nature Editorial. Not-so-deep impact. Nature 2005, 435, 1003-1004.

3. Garfield, E. Citation Analysis as a Tool in Journal Evaluation: Journals can be ranked by frequency and impact of citations for science policy studies. Science 1972, 178, 471-479.

4. Nature Research. Author Insights 2014. Figshare 2015.

5. Beall, J. Predatory publishers are corrupting open access. Nature 2012, 489, 179.

6. Stern, B.M.; O'Shea, E.K. A proposal for the future of scientific publishing in the life sciences. PLoS Biol. 2019, 17, e3000116.

7. Zongker, D. Chicken Chicken Chicken: Chicken Chicken. Ann. Improbable Res. 2006.

(C) 2020 by the authors. Licensee MDPI, Basel, Switzerland. This article is an open access article distributed under the terms and conditions of the Creative Commons Attribution (CC BY) license (http://creativecommons.org/licenses/by/4.0/). 


\title{
11 Moving Beyond Metrics
}

\author{
Valentina Ghimpau
}

"In the arena of human life the honours

and rewards fall to those who show

their good qualities." - Aristotle

Nowadays, it is vital for the quality of science to quantify and compare the scientific output of researchers. Because of the high-tech era we are living in, comparison by reputation and direct assessment of contributions to the research is no longer possible.

The pressure of delivering a high standard of research articles is best summarized in the archetype "publish or perish".

Authors are assessed throughout different quantitative methods, like h-index, journal impact factor (JIF) and number of publications [1], but these methods are overestimated and it places societal importance in second place. If you regard the problem from a larger point of view, using all these indicators to assess a person's scientific importance is not completely wrong because the papers published in journals with higher impact factors tend to be superior and more relevant than the journals with lower ones.

I personally think that it is time to move forward with modern assessment criteria for current research. The research, no matter what field it serves, should have an impact in that specific domain, inspiring others to continue to develop and to make a substantial contribution to the scientific community.

There should always be multiple measures, including both qualitative and quantitative so that the evaluation is valid.

The evaluation system should not contain info only about h-index or Journal Impact Factor, but it should be a vector composed of the number of publications, number or reads, number of citations, among journal's index [3], author's contribution and the weight for articles with many coauthors should be discounted by their number. Maybe a PageRank index should be considered, too. It uses an algorithm that considers not only the number of citations but also the actual impact of each citation.

Even with so many criteria, the valuation of researcher can be biased [2].

Going back to the fundamental question about how can research be evaluated and a researcher awarded, it all seems to crystallize while embracing a simple 
concept: being part of the academic world comes with the major obligation of acting fair and being honest about your work. Thereby, incorrect practices should not exist due to the moral spine in each of us. I truly believe that research should be evaluated not only quantitatively, but qualitatively. Easy to say, hard to do, but maybe using anonymous research-assessment tools, other researchers in the field can offer guidance in the difficult task of evaluating and rewarding the ones that deserve it the most. The counter-argument that one could have subjective feelings that could bias the assessment fails when we take into consideration the principle of being fair that I have discussed earlier.

Lately, some are rushing to conclusions and are preaching about the death of the impact factor, but these assertions can surely be considered to be greatly exaggerated. Nevertheless, even the existence of these assumptions should trigger an alarm and multidisciplinary committees should join forces and come up with a more valid list of criteria for assessing the scientific papers. It will require enormous amounts of work, but a better evaluation and-in consequence-a better reward system for researchers, is for sure possible.

\section{References}

1. Wilsdon, J.; et al. The Metric Tide: Report of the Independent Review of the Role of Metrics in Research Assessment and Management (HEFCE, 2015).

2. Gingras, Y. Dérives et effets pervers de l'évaluation quantitative de la recherche: sur les mauvais usages de la bibliométrie. Revue Int. PME 2015, 2, 7-14.

3. Yaminfirooz, M.; Ardali, F.R. Identifying the Factors Affecting Papers' Citability in the Field of Medicine: An Evidence-based Approach Using 200 Highly and Lowly-cited Papers. Acta Inform. Med. 2018, 26, 10-14.

(C) 2020 by the authors. Licensee MDPI, Basel, Switzerland. This article is an open access article distributed under the terms and conditions of the Creative Commons Attribution (CC BY) license (http://creativecommons.org/licenses/by/4.0/). 


\section{Mathematics in Current Science and in Scientific Evaluation}

\section{Irma Ayes Rivera}

Curiosity killed the cat, says a Latin American proverb, arguing that by going where it is not called, the cat died. However, from my father, I have learned that without curiosity, the great discoveries could not have happened, or they would have taken a little longer. It is not only this fact that my father gave to my sisters and me, but also, to build a critical mind and understand from his professional area (the teaching of medicine) to work with a humanistic approach. Now, while I'm doing my PhD, a lot of what I learned at home has more relevance. Some of these discussions are summarized by the mathematician Eduardo Sáenz de Cabezón in his presentation regarding what is Mathematics useful for? [1]. He explains how mathematics not only helps us in logical thinking-an indispensable element in science development-but also contribute to being in the world in a more human and full manner. While, during childhood, Sáenz explained, mathematics stimulates our curiosity, during higher education, it enables us to understand the logic and interpretation of data and results, allowing us to be more critical, both as a researcher and as a citizen. In this sense, within his "kit of skeptics", Carl Sagan suggested some tools to rationally argue and recognize some fallacies or errors [2]. Two of these (without letting aside the other seven), are the quantification and the use of Occam's Razor; the first refers to the need to be able to measure, in the case that there are quantitative data to the explanation we give or is given to us, while the second within the scientific method states that, in equal conditions, the simplest explanation is usually the most likely. These two recommendations have in common the use of mathematics in the evaluation of scientific arguments, and the probability term used in Occam's principle implies the inherent uncertainty that exists when analyzing the data in a statistical way.

Nowadays, science relies on statistics for both its development and for research evaluation. We just need to look at what the introduction of the p-value in the 1920s by Ronald Fisher and the hypothesis theory of Jerzy Neyman and Egon Pearson has allowed us [3]. Indeed, many studies conclude their findings according to the evaluation of $p$-values less than 0.05 , this is, we accept that one result in 20 will be a false positive (Type I error), if the null and alternative hypothesis were appropriately defined. However, even though it is based on tests and numerical data, it is also subject to the sample, its interpretation and even hacking. Therefore, how can we evaluate the 
results of research and researchers? It is true that mistakes and failed attempts are a constant in science and are intellectual incentives, but when it is necessary to evaluate a set of researches, how can they be objectively comparable? One of the possible solutions is through its replicability, which is often not possible to do because of lack of resources, unavailable data or for the confidence we have in the peer-review system of scientific journals. In fact, as researchers "There is no cost to getting things wrong, the cost is not getting them published" (Brian Nosek in [4]). This situation is due to the high competitiveness that currently prevails in science and to the evaluation and award processes of universities and research institutions, based on the quantity of publications and the impact factor of the journals. This leads to future hiring, labor promotions and financing of future research, which is not bad per se, because it allows us to have elements for measuring the performance of the research and its developers. However, in my opinion, this has dehumanized science and its purpose, creating a progressive number of annual publications without generating, in many cases, a true contribution to science itself and although, in some cases, the contribution may be significant, by showing other contexts of the current problems, ultimately the use of these results depends on the will of the decision makers. Examples of this are the two most read articles in the Environmental Research Letters (with an impact factor of 6.192 in 2018): Quantifying the consensus on anthropogenic global warming in the scientific literature and The climate mitigation gap: education and government recommendations miss the most effective individual actions, with 1,003,096 and 412,158 downloads each one in mid-July 2019 [5]. The 1st article is very clear in its title, while the 2 nd, calls to see beyond the global agreements in relation to global warming and what is being neglected, the mitigation measurements from the community.

Finally, it is necessary to emphasize that although mathematics, especially statistics, has allowed significant advances to be made in many areas of science, they have a limit in our logical understanding of the processes in nature, not only when formulating abstract models of our reality, but also in the evaluation of research. In the current world, which leads us to compete in many facets of our lives, unless the paradigm of why we do science does not change, it is very difficult to recommend the best way to evaluate and reward our work.

\section{References}

1. De Cabezón, S.E. ¿para qué sirven las matemáticas? (for what are useful the mathematics?) In BBVA. Available online: https://aprendemosjuntos.elpais.com/ especial/para-que-sirven-las-matematicas-eduardo-saenz-de-cabezon/ (accessed on 10 July 2019). 
Global Benefits of Open Research. The 2019 MDPI Writing Prize

2. Sagan, C. The Demon-Haunted World: Science as a Candle in the Dark, 1st ed.; Headline Book Publishing: London, UK, 1997; ISBN 0-7472-5156-8

3. Biau, D.J.; Jolles, B.M.; Porcher, R. P-value and the theory of hypothesis testing. Clin. Orthop. Relat. Res. 2010, 468, 885-892. doi:10.1007/s11999-009-1164-4.

4. Trouble at the lab. In The Economist. Available online: https:/ / www.economist.com/ briefing/2013/10/18/trouble-at-the-lab (accessed on 16 July 2019).

5. Environmental Research Letter. Available online: https://iopscience.iop.org/journal/ 1748-9326 (accessed on 22 July 2019).

(C) 2020 by the authors. Licensee MDPI, Basel, Switzerland. This article is an open access article distributed under the terms and conditions of the Creative Commons Attribution (CC BY) license (http://creativecommons.org/licenses/by/4.0/). 


\section{Achievement of the Paper and Its Honor for a Researcher}

\section{Aqiang Lin}

For a general scientific researcher, we often think about a question: can there be no other contribution besides publishing a paper? If an entire lifetime is devoted to publishing a thesis for publishing a paper, what contribution do these researchers make to society? This is a very interesting discussion.

So what makes an excellent academic paper? It should contain the following five elements: innovation, readability, amount of information, references, and signature. (a): For innovative, it is an innovative and remarkable (unexpected or surprising) result of scientific research, which seems to have a wide range of significance outside the field, and a creative, high-level and significant latest research achievement in basic research and applied research. (b): The readability of a scientific paper is of vital importance and should be highly valued by the authors. Moreover, the readability of a paper is determined by the following factors: whether the research work has made substantial progress, whether the conclusions obtained are reliable, and whether the results are profound and enlightening. Simultaneously, the author should make a complete conception of the paper, embody strict logical thinking, and make repeated deliberations on the method of exposition, the material of the content, the explanation of academic thought, the introduction of the research background, etc. The objective is to make the paper precise in structure, full in content, complete in exposition and strong in logic. In fact, the readability of a paper means that after reading a paper, the reader can understand what problems you want to say and how to solve them. It does not require the reader to fully understand the whole content of your paper.

However, the ability of many papers to contribute and influence is limited, so why publish a paper? Researchers, especially in the early stages of their careers, are under increasing pressure to publish papers. Many researchers could be afraid of being unknown, of not catching up with hot topics and of not delivering good articles. Because without reputation and achievements, there will be no funds for scientific research, no students, no self-support, and no good teaching posts. This is because the publication of the paper has become an important benchmark for winning lifelong appointments, passing annual assessments and government research assessments. In addition to simply satisfying their own requirements or for scientific reasons, there are a large number of other driving factors that prompt scholars to publish their papers. 
Then, how to evaluate the impact of the paper? Scientific research achievements should undergo formal, content and historical evaluation after they are published. The first is based on the impact factors of journals, ranking of fields, citation of papers and other indicators. The second is based on peer analysis and comparison of information reported by researchers. The third is based on scientific contributions tested over time. In short, the value of the life of scientific researchers is ultimately measured on a historical scale. The value of scientific research lies in increasing human knowledge and promoting human progress. Therefore, the importance of research results is judged by their contribution to human knowledge and development.

For the achievement of the paper, it could be due to the very high expectations of people regarding a scientific researcher. The reason why science is science lies in its exploration and uncertainty. Scientific research is the exploration of the unknown world. Since it is exploration, a large number of failures is the mainstream. It is normal that most of us have not made outstanding contributions in this lifetime. For the vast majority of scientific research workers, who have been busy for a lifetime, it may be very difficult to make major breakthroughs. However, from the perspective of the group, science and technology are progressing. In my opinion, I simply like the process of writing and publishing a paper after an academic investigation, as well as the sense of achievement when the paper is published. So, I will be more proud of publishing my own paper, this pride is accompanied by achieving honor in my lifetime.

(C) 2020 by the authors. Licensee MDPI, Basel, Switzerland. This article is an open access article distributed under the terms and conditions of the Creative Commons Attribution (CC BY) license (http://creativecommons.org/licenses/by/4.0/). 


\section{Judging Research: Is There Even a Need of Evaluating the Research?}

\section{Prashant Chauhan}

What is research? Research is a process that allows people to explore the facts and knowledge and ascertain them in a systematic way, allowing enlightenment from unknown to known. This statement is composed of two main keywords underlined above. Most of us are aware of the literal meaning of both the words, but in terms of research, it turns out these words are figurative. The fact is, information can always be generated by doing experiments, but the interpretation and analysis of the datasets, clearly depends on the researcher's own perspective, the nature of the question being asked at the beginning and the approach towards it, thereby giving a unique figurative meaning to both the terms. It could be explained further by taking a hypothetical example, suppose there are two researchers, A and B, assigned with a task of analyzing and interpreting the datasets representing the number of restaurants in some small town $(\mathrm{X})$. The data represents the consumption of raw materials used in restaurants like-spices, meat, vegetables, milk, etc. For researcher A, it might reflect simply what people are used to eating in this region. Such an observation is supported by the logical argument made by researcher $\mathrm{A}$ that the restaurants are making dishes that people tend to consume more often and thereby, trying to maximize profits. However, what if researcher B sees the problem in an entirely different perspective and argues that the raw material consumption in the restaurants does not necessarily indicate that the observation made by researcher $\mathrm{A}$ is true. For supporting his hypothesis, researcher B proposes that the restaurants are producing the dishes made from inexpensive raw materials, and people are accustomed to consuming those dishes, which, in turn, shaped their palette preference and dietary behaviors over a long period. Well, such an observation could only be made if the datasets are analysed systematically and researcher B considered the fact that other restaurants are following the same trend of using inexpensive raw materials for making dishes. Revealing the fact that restaurants in town $X$ are involved in tough competition with each other and produce foods that generate more profits while incurring minimal manufacturing cost.

This example elucidates how the approach of doing research can produce drastically different results in the end. The distinctive methods of doing research were developed over millennia by logical analysis of information by visionaries and several revolutionary minds who existed in these timelines. Essentially research exhibits a 
funneling effect whereby, one starts with experiments, observations, analysis of the dataset and ends up in producing few key findings. Irrespective of the discipline in which the research is conducted, the pattern that emerges is the same as mentioned in ancient to modern bibliographic literature. It turns out that every individual is driven by a different motivation to do research. These commonly include:

1. Desire To Be Famous,

2. For The Betterment Of People,

3. In pursuit of Knowledge,

4. Monetary Gains By Translating The Research,

5. Personal Reasons,

6. Reading, Writing, Analysing, and Sharing Information,

7. To Answer Some Long-Standing Questions In History,

8. To Eliminate Doubts, Abolish Lies, Disapprove Myths and Supernatural phenomena.

Every researcher should realize that research not only requires accomplishing certain predefined objectives within a timeframe, but it should begin with a meaningful concern. Therefore, it is very important to choose a topic that is worth all the efforts. Rigorous examination and brainstorming thus become essential to yield credible, coherent and impactful results. The ethical and moral code in research should be strictly followed in reporting the finding(s). If these aforementioned ways of doing research are followed correctly, then the question 'Who Should Judge the Research' becomes irrelevant. According to me, more important is what impact does the research have on humankind. Universally, all the findings are not path-breaking and change the course of further research, but we should appreciate that every discovery is unique in its own way if delivered truthfully no matter how small or big it is, or which disseminating media is used. Even if a significant finding is not acknowledged or is oppressed at first, it is destined to be rediscovered because what may be inconsequential to some may turn out to be a treasure for others. Nonetheless, if needed, research should be evaluated on the criterions like narrative, commitment, peer review, triangulation, reproducibility, transparency, auditing and economization and the translational output or impact.

Research conducted so far in areas of science and technology and art and humanities have allowed the people to excel their views and expand their knowledgebase. Through research, we evolved from logically oblivious cave dwellers to inquisitive thinking entities capable of processing information, making arguments, and improvising to overcome hurdles. We have come to a point in our timeline where 
critical decisions made by humanity will dictate its future course and existence. Only time will tell whether we will perish on our beautiful blue planet, or we would break the bounds of physics, explore the mysteries of the quantum world to the vastness of the universe, ultimately finding the true purpose of our existence. For this fantasy to come true, it is imperative that humans should realize that the true meaning of our existence is beyond waging wars, destroying nations, inflicting pain, suppressing intellect, spreading blasphemy and reporting false research for trivial gains. We should understand that the research benefits every one of us if the moment is seized together. We need to progressively keep working together, not just as individuals but as a synchronized conscious system that generates, spreads, and translates the research into everything that is possible. In the end, transcend into a higher civilization and ask ourselves where we go from here. In my view, this would be the greater evaluation of research and the ultimate reward that humanity will ever be able to fetch from it.

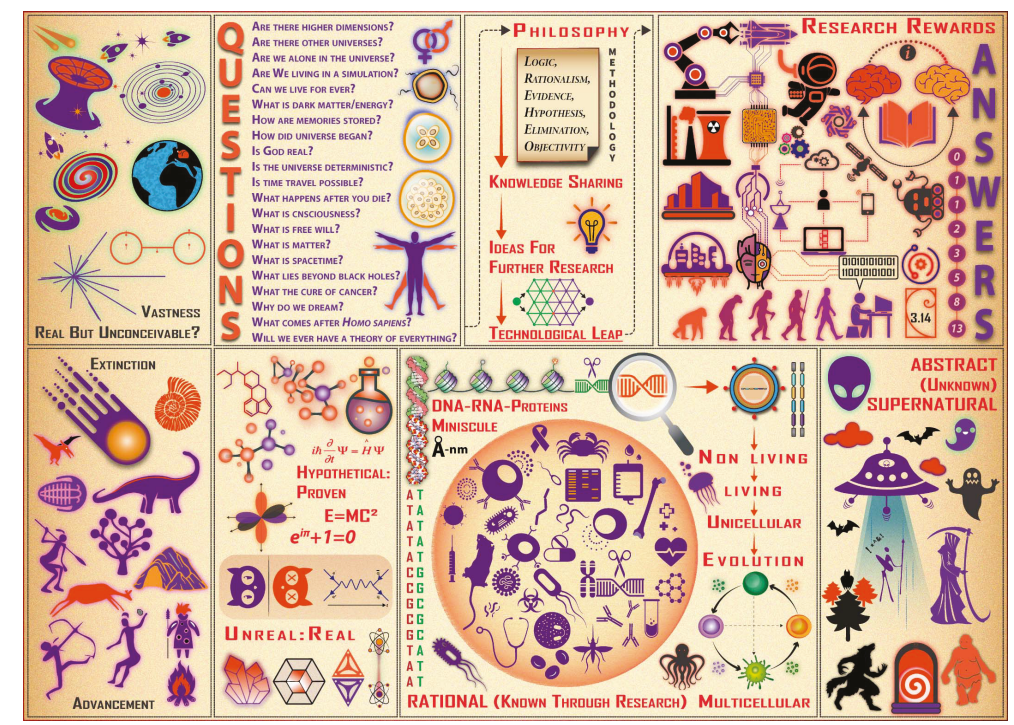

Figure 1. A concise map of research, methodology, and some big questions regarding its implications on humanity.

(C) 2020 by the authors. Licensee MDPI, Basel, Switzerland. This article is an open access article distributed under the terms and conditions of the Creative Commons Attribution (CC BY) license (http://creativecommons.org/licenses/by/4.0/). 


\section{Research Quality and How to Find It?}

\section{Luisa Rojas}

Darwin spent 30 years analyzing data obtained during the Beagle expedition and he later published his work in the book On the Origin of Species in 1859. This 30-year time gap between data collection and publication is not quite aligned with the hypercompetitive publish or perish mentality of the current mainstream of science. According to one study, for the most prolific researchers (who publish an article every 5 days), the real motivation is not to disseminate one's science but to win more grants or acquire more direct financial incentives. One example of this was the controversial policy of the Chinese government paying cash to researchers who published scientific manuscripts, with extra incentives for publications in well-respected journals. But how do these policies affect the quality and reliability of the research? Is there a way to reward research and researchers without corrupting the system and promoting poor quality publications?

\section{Perverse policies or perverse researchers?}

One policy commonly adopted worldwide is to reward researchers with an increase in salary or a promotion based on the number of publications. The idea behind this is to stimulate productivity of researchers. Unfortunately, these policies may also increase the rate of substandard publications, falsification of data, and fraud in publications. With these incentive-based policies, there has also been an increase in organizations that help researchers with the publication process. Some companies offer the option of writing the complete paper and there are other cases where these companies had manipulated the peer-review process in journals by fabricating fake emails to well-known researchers. However, these types of policies also occur at different levels of the research and publication process. In one example of fraud at the journal level, the journal opened the scope and increased the single-author publications, the editorial board have no expertise in those diverse topics and when it was banned, published several issues to get as many articles as possible published before the ban was effective.

\section{How did the policies become perverse?}

Some literature links the decline in research quality with the overall reduction in grant funding from organizations like the National Institutes of Health. This decline in funding induces a pressure to reduce the time spent analyzing data and developing more elaborate ideas, towards more short term goals and projects. This pressure 
affects all the researchers, even the most prolific. One study found that the driving forces for hyper prolific researchers are the fear of the publish or perish mentality, financial rewards, and promotion to tenure. That is the reason other initiatives to promote research quality are perverse. For example, rewarding researchers based on the number of citations is perverse because of the increase in the reference list and self-citing. Another measure of quality is the number of grants acquired. This policy results in an increase in the time researchers spend writing and reviewing grant proposals, focusing more on the quantity of grants and not on the quality. This also suppress creativity and original thinking and forces them into short term thinking.

\section{How can the system be improved?}

The reward system should be improved at all levels.

At the funding agency level: increase the amount of funding, strengthen grand review panels and review systems, invest resources in creating more meaningful metrics and not eliminating the actual panels but reduce their importance in decision making. For example, some researchers are moving to Journals that do not use Journal Impact Factors because of the bias towards English language.

At the university level: Promote an open discussion about ethics and highlight corruption to learn from mistakes. Strengthen the academic programs with responsible conduct of research courses at undergrad and graduate level. PhD programs should build character and prepare students to service humanity through science, encourage leadership, teamwork, project management, communication skills and mental health. Also, inform the students about other career paths available besides academia. For example, science policy, administration, law, scientific writing, science curriculum and other non-research careers that currently receive less attention from the universities.

At the researcher level: consider that researchers should be evaluated and rewarded according to a balance between successful trainees and publications, based on all the achievements of their careers and establish different categories for junior researchers. At the publishing level: some initiatives to tackle these problems are to promote open access journals and preserve localized publications. In general, reward academics that use open science, open access journals, and open science clouds that allow researchers to compare, analyze, and discuss data.

At the policy level: it is important to create an environment that promotes interdisciplinary and collaborative work and through the improvement of the facilities and the support for data sharing and reproducibility platforms, make it possible to cultivate a vibrant intellectual interdisciplinary and diverse community. 
The unethical practices in science decrease the general public respect and trust in science and generates a broken legacy for future generations. For that reason, it is necessary to think of a new way to reward the researchers for their contributions to science. To combat unethical practices, it is important to increase the investment in science rewards, promote ethical practices in all the institutions and in all levels, as well as create free access to platforms and reward the use of those that facilitates reproducibility. Finally, rewarding faculty and young researchers will reduce fraud and favor an environment of quality over quantity. By instilling these programs, the judging and reward policies in sciences will facilitate better profits and generate knowledge that will be the most reliable and useful for humanity.

(C) 2020 by the authors. Licensee MDPI, Basel, Switzerland. This article is an open access article distributed under the terms and conditions of the Creative Commons Attribution (CC BY) license (http://creativecommons.org/licenses/by/4.0/). 


\title{
16 Judging Research: How Should Research and Researchers Be Evaluated and Rewarded?
}

\section{Fenik Kaml Muhammed}

There is a growing demand for transparency and accountability in research evaluation that encourages researchers to develop a comprehensive list of evaluation tools and techniques with their explanation of techniques and ideas that can be applied to assess the value of research. The comprehensive evaluation of advantages and disadvantages of various approaches need to be considered. Long and short term measuring tools need to be considered, for example in the short term measure, the number of publication of researcher, and the audience in the long term measure [1].

To judge the research and researcher, certain points needs to be considered and focused;

\begin{abstract}
A strong abstract can clearly describe the purpose, design of the research being conducted, as well as the problem that paper the is attempting to resolve. An abstract also tells the reader about a brief interpretation of the results. The research from the first overview can be evaluated from the abstract as to whether this study or research has a significant impact in the future study and deserve to be explored in detail or not. [3].
\end{abstract}

\section{Objectives}

The author has clearly described the objectives in a detailed manner not in the beginning of the manuscript but in the last paragraph of the introduction after performing an excellent effort of reviewing the current literatures and finding the niche of their own study to present the objectives; it is essential in any paper to have a clear aim of what you are going to be writing about. Although it appears a small point, however, it has a great impact in that it directs the reader to find out how the author followed the objectives and targeted their own aims. The researchers need to clearly define the research question and step by step evaluate and discover the answer to this question and allow the reader to follow the research and identify the relationship and association with other studies [2]. For instance, let the readers distinguish true experimental designs with random assignment from pre-experimental research designs [2]. 


\section{Technical issues}

Using excellent abbreviations for a complex topic that makes the manuscript short and meaningful with saving many words.

An excellent study when performed by a great researcher explains each point of the experimental method in a way that enhances the reader to have the pleasure of discovery and divulges essential details [4].

Presenting a paper with a diagram is worth a thousand words, which lets the reader use their imagination [4].

No personal pronouns are used in the manuscript, in other words, the manuscript is written in a formal academic writing style [4].

An excellent explanation of the result and comparison with other studies to indicate consistency with the current study [4].

The evaluation of research needs to be based on the field of subject area of wide interest of the current science. For example, studies nowadays are focusing on digital instruments and gradually, items are becoming globally digitized rather than using conventional instruments.

To what extent the author has a previous background in this topic, is the idea too simple or an extraordinary idea and worth publishing and even citing. In addition, the author should be evaluated by the number of citations of papers that have been published. Sometimes the paper is cited and read by a large number of other researchers, this means the work has been performed in sequence and answered the relevant questions that the majority of other researchers are looking for.

The evidence suggested that for judging a study or for researcher evaluation, this needs to be performed by an expert with more than twenty years in research.

\section{Referencing}

When referencing a previously published article, the author read a wide range of articles that carefully selected the paper to make the claim to support their own paper, especially those that contain little evidence for the claim and make the paper shine in comparison [4]. For evaluation of high-quality research, the researcher needs to select the most appropriate reference for his/her study. Probably not all the references are liable to be included, the point is, a recognizable journal with a clear impact factor and reputation globally need to be focused on and most importantly, the most current reference used instead of the outdated references of the last 50 years, apart from some gold standards that can be used anytime [2]. 


\section{Data analysis}

The researchers must have a clear background for statistical analysis and the methods that are used for appropriately collected data, and assumptions for their use met. In addition, the presentation of data analysis is very essential for performing high quality research, the data need to be presented in tables or figures must have a clear indication of the variables' impact and be clearly labeled [2].

\section{Language and originality}

Language is also another parameter to be considered when the research scales are evaluated. Strong academic language gives power to the current literature and makes it stand out and allow the reader to enjoy the flow of the writing and scene of the science. The originality of the research is also another crucial point that needs to be considered in evaluating an excellent study and researcher. To what extent is the idea and its content is unique and novel? Whether the writing format is totally taken from other ideas and paraphrased or copied directly. This affects the quality of paper.

To sum-up, this essay described certain points that are essential for choosing a study and researcher, at least three to five experts with twenty years of research are required to evaluate whether this study or person should be rewarded or not under their practical experience and certain standard criteria that are essential for this purpose.

\section{References}

1. Available online: https://www.rand.org/randeurope/research/projects/evaluatingresearch.html (accessed on 15 July 2019).

2. Available online: https://blog.efpsa.org/2011/08/01/how-to-critically-evaluate-thequality-of-a-research-article/ (accessed on 12 July 2019).

3. Available online: https://www.wikihow.com/Evaluate-a-Research-Paper (accessed on 20 July 2019).

4. Roya, W. Skillful writing of an awful research paper. Anal. Chem. 2011, 83, 633-633. doi:10.1021/ac2000169.

(C) 2020 by the authors. Licensee MDPI, Basel, Switzerland. This article is an open access article distributed under the terms and conditions of the Creative Commons Attribution (CC BY) license (http://creativecommons.org/licenses/by/4.0/). 


\section{Judging Research: How Should Research and Researchers Be Evaluated and Rewarded?}

\section{Subhan Danish}

For the evaluation of any research, assessment of researcher ideology and financial interests are two major and basic aspects. During the assessment of research, a description of a well-defined question or problem related to past and present is very important, as it significantly diverts the attention of any reader towards research [1]. Analysis and presentation of data is a 2nd major aspect in that regard. It delivers solid evidence related to critical assumptions, contrary to findings and alternative interpretations including original sources, alternative perspectives and criticism. Good research may use anecdotal evidence, i.e., selected to illustrate a concept. However, it does not rely on them to draw conclusions. In addition, peer review by qualified experts played an imperative role in the improvement of research by elevating the possible errors, limitations and contradictory evidence. This does not mean that only peer-reviewed studies are useful or everything published in professional journals is correct. However, the process of peer review encourages the open debate about issues or problems that are discussed in a research article [2].

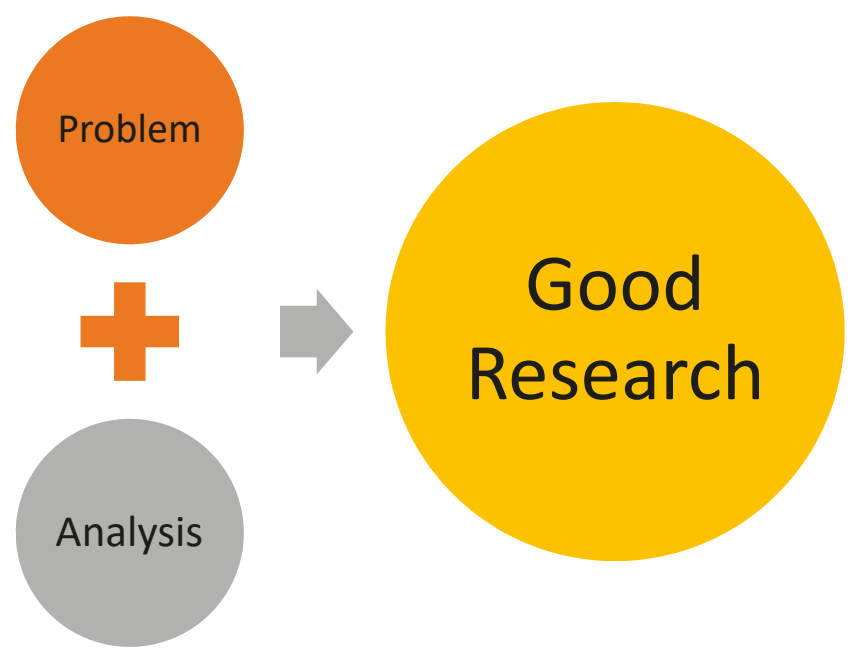




\section{Type of Peer Review}

Peer review comes in many types, i.e., single- or double-blind peer review, open or transparent peer review. In single-blind peer reviews, authors do not know about the reviewer's identity and the journal does not publish referees reports. In double-blind peer review, neither the author nor reviewers know the identity of each other and the journal does not publish referees reports.

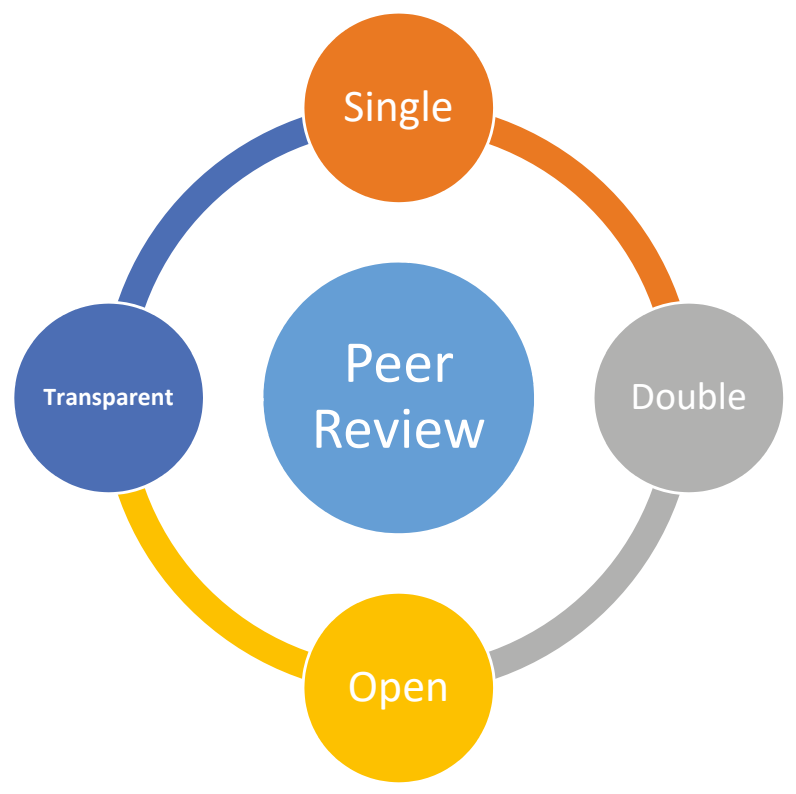

Desirable Practices for Judging any Research As a reviewer, some important points should be kept in mind during the evaluation of any research. These may be:

1. Timely reporting.

2. Be honest during the evaluation of research.

3. Check each source citation. Either the citation source is primary or secondary.

4. Carefully understand the research questions and associated broader issues.

5. Assess the critical assumptions in connection with the analysis method (validated or rejected).

6. Examine the logical links between results, conclusions and implications.

7. Provides adequate references.

8. Indicates funding sources particularly any that may benefit from research results. 


\section{Time report}

Both the editor and authors are keenly interested in smooth and timely reporting during peer review of any manuscript. By adhering to the deadlines set out by editors, reviewers also minimize the risk of issues for the authors. When authors submit their papers to any scientific journal, they also hope to have a decision on publication as soon as possible [2].

\section{Honest and Constructive}

Power always remains in the hands of the reviewers. Most editors are dependent on the reviewers' comments for the acceptance, revision or rejection of any manuscript. It is necessary that a reviewer should remain honest and counteractive during a review. Rather than rejecting the manuscript, the reviewer has large responsibilities to give suggestions that can improve the quality of the research article for further necessary action. According to my point of view, authors must get at least one chance to improve the quality of the article rather than straight away rejection. Testing the success of any change to peer-review practices requires that journals approve a modified review process for a limited period to assess the liquidity of change as an outcome [1].

\section{Frequency of peer review}

A reviewer must keep in mind that when he is invited to peer review it might not be a one-off task. Typically, a paper must go through two to three review cycles before publication. This is a positive attitude that not only increases the credibility of the research article but also depicts the constructive behaviour of a reviewer [1,2].

\section{How scientists should be rewarded}

As the world of science becomes more complex, more studies require large teams of specialists. Yet in the world of academic publishing, the first and last authors of a journal article receive the lion's share of the credit. The names in the middle of the author list, the collaborators, get very little recognition, even if their contributions are large and essential. McNutt, previously editor-in-chief of the journal Science, discussed one change that would reward all collaborators and encourage more team efforts. Paula Stephan, professor of economics at Georgia State University, suggested that the scientific community develop more high visibility awards for group efforts. So, it is suggested that all the authors should be rewarded equally as the first and last author. 
Judging Research: How Should Research and Researchers Be Evaluated and Rewarded?

\section{References}

1. Gura, T. Peer review-unmasked. Nature 2002, 416, 258-260.

Neff, B.D.; Olden, J.D. Is Peer Review a Game of Chance? Bioscience 2006, 56, 333-340.

2. Clark, A.; Singleton-Jackson, J.; Newsom, R. Journal editing: Managing the peer review process for timely publication of articles. Publ. Res. Q. 2000, 16, 62-71.

3. Assessing Value in Biomedical Research: The PQRST of Appraisal and Reward John P. A. Ioannidis. Muin J. Khoury JAMA 2014, 312, 483-484.

4. Benedictus, R.; Benedictus, F.; Ferguson, M.W.J. Fewer numbers, better science. Nature 2016, 538, 453-455.

5. Hicks, D.; Wouters, P.; Waltman, L.; de Rijcke, S.; Rafols, I. Bibliometrics: The Leiden Manifesto for research metrics. Nature 2015, 520, 429-431.

(C) 2020 by the authors. Licensee MDPI, Basel, Switzerland. This article is an open access article distributed under the terms and conditions of the Creative Commons Attribution (CC BY) license (http://creativecommons.org/licenses/by/4.0/). 

MDPI

St. Alban-Anlage 66 4052 Basel

Switzerland

Tel. +41616837734

Fax +41613028918

www.mdpi.com

MDPI Books Editorial Office

E-mail: books@mdpi.com

www.mdpi.com/books

\section{MDPI}



